\title{
Determinação das taxas de renovação das águas no complexo estuarino de Paranaguá
}

\author{
Determination of water renewal rates in the Paranaguá estuarine complex
}

Jessyca Petry Dalazen* ${ }^{\oplus}$, Cynara de Lourdes da Nóbrega Cunha' $₫$, Ricardo Carvalho de Almeida1 $₫$

口-

\section{RESUMO}

Este trabalho investiga a renovação das águas no Complexo Estuarino de Paranaguá (CEP), localizado no estado do Paraná, Brasil, usando o sistema de modelagem computacional SisBaHiA ${ }^{\oplus}$. Um modelo de circulação hidrodinâmica, para a definição dos padrões de circulação, e um modelo de transporte Euleriano, para calcular a taxa de renovação (TR), idade da água (IA) e escoamento residual, foram implementados. A TR, a IA e o escoamento residual foram determinados para diferentes cenários hidrodinâmicos, com períodos representativos de verão e de inverno e, consequentemente, com diferentes forçantes (maré, vazão ou vento) com o objetivo de identificar as possíveis áreas de estagnação. Os resultados obtidos mostram que a maré e as vazões fluviais são os forçantes de maior importância na renovação das águas do CEP. Em todos os cenários foram identificadas duas possíveis áreas de estagnação, que apresentam menores TRs e maior IA, quando comparadas com outras regiões, a saber, a região da baía dos Pinheiros e a região próxima à cidade de Paranaguá. Durante o verão e considerando todos os forçantes, as TRs na região da baía dos Pinheiros e na região próxima à cidade de Paranaguá são menores que 95\%, enquanto nas demais regiões do CEP os valores são superiores a 95\%.

Palavras-chave: renovação das águas; complexo estuarino de Paranaguá; modelagem hidrodinâmica; SisBaHi ${ }^{\oplus}$.

\begin{abstract}
This work investigates the water renewal in the Paranaguá Estuarine Complex (PEC), located in the state of Paraná, Brazil, using the SisBaHiA ${ }^{\circledR}$ computer modelling system. A hydrodynamic circulation model, for the definition of hydrodynamic circulation patterns, and an Eulerian transport model, for the computation of the water renewal rate, water age and residual circulation, were implemented. The water renewal rate, water age and residual circulation were computed for different hydrodynamic scenarios, with representative summer and winter periods and, consequently, with different forcings (tide, river flow or wind), in order to identify possible stagnation areas. Results show that the tide and the river flows are the most important forcings in the water renewal of the PEC. Two possible stagnation areas were identified in all scenarios, which presented lower renewal rates and higher water ages when compared to the other regions, namely, the Pinheiros bay region and the region near to Paranaguá city. During the summer and taking into account all the forcings, renewal rates in the Pinheiros Bay region and near the city of Paranaguá are less than 95\% whereas in the other regions of the PEC, the values are higher than 95\%.
\end{abstract}

Keywords: water renewal; Paranaguá Estuarine Complex; hydrodynamic modeling; SisBaHiA ${ }^{\circledast}$.

\section{INTRODUÇÃO}

Estudos que possibilitem conhecer os processos de renovação de constituintes em corpos d'água são uma importante ferramenta de gestão, pois possibilitam conhecer os processos de mistura e o tempo que os constituintes ficam retidos no seu interior, bem como quais são os forçantes mais importantes nesses processos (maré, vento, vazão fluvial etc.), facilitando a identificação de possíveis áreas de estagnação. Existem vários parâmetros que podem descrever esses processos de renovação, como, por exemplo: o tempo de residência, a taxa de renovação (TR) e a idade da água (IA) (MONSEN et al., 2002). De modo geral, estuários com maiores TRs e tempos de residência pequenos, ou com águas mais "novas" (IA menor), teriam menos problemas relacionados à qualidade de água (KENOV; GARCIA; NEVES, 2012).

A definição da circulação hidrodinâmica é o passo inicial nos estudos sobre os processos de renovação e serve como base para que vários outros estudos possam ser realizados. Muitos trabalhos dedicados ao estudo dos processos de renovação das águas em estuários e baías baseiam-se na modelagem numérica:

- Cucco e Umgiesser (2006) investigaram a capacidade de renovação da Lagoa de Veneza, localizada no nordeste do Mar Adriático, utilizando um modelo hidrodinâmico bidimensional; 
- Lopes e Dias (2007) estudaram a circulação residual, o tempo de residência e a dinâmica dos sedimentos na lagoa Ria de Aveiro, em Portugal, por meio de um modelo hidrodinâmico bidimensional e de transporte de sedimentos;

- Roversi, Rosman e Harari (2016) analisaram as TRs das águas do Sistema Estuarino de Santos, localizado no litoral do estado de São Paulo, considerando os efeitos de maré astronômica, das vazões fluviais afluentes de verão e inverno e do gradiente horizontal de salinidade;

- Xu, Mao e Jiang (2016) utilizaram um modelo numérico tridimensional com um módulo lagrangeano de rastrear partículas para simular as correntes residuais na Baía de Xiangshan, na China.

Este trabalho teve o principal objetivo de quantificar a renovação das águas do Complexo Estuarino de Paranaguá (CEP), a partir de alguns indicadores - TR, IA e escoamento residual, para os diferentes forçantes (maré, vento e aporte fluvial) - e, assim, avaliar a influência desses sobre o processo de renovação. Como consequência, é possível, ainda, definir possíveis regiões de estagnação no CEP. Uma importante contribuição deste trabalho é o tratamento usado para a obtenção dos dados de vento, para regimes de vento característicos de verão e inverno, considerando toda a extensão do CEP.

\section{METODOLOGIA}

\section{Área de estudo}

O CEP está localizado na Região Sul do Brasil (Figura 1), na porção centro-norte do litoral do Paraná, tendo três conexões com o Oceano Atlântico: o canal Norte, localizado entre a Ilha do Superagui e a Ilha das Peças; o canal Sueste, localizado entre a Ilha das Peças e a Ilha do Mel; e o canal da Galheta, localizado entre a Ilha do Mel e Pontal do Paraná. É composto de dois corpos d'água principais: as Baías de Paranaguá e Antonina (eixo leste-oeste) e as Baías de Laranjeiras e Pinheiros (eixo norte-sul), totalizando uma área de $612 \mathrm{~km}^{2}$ (LANA et al., 2001). Tem grande importância econômica no setor pesqueiro, industrial e turístico, associada às intensas atividades dos dois portos localizados no CEP, o Porto de Paranaguá e o Porto de Antonina (Ponta do Félix). A Figura 1 mostra a batimetria do CEP, obtida a partir das cartas náuticas n $1.820, \mathrm{n}^{\circ} 1.821$ e n 1.822 , da Diretória de Hidrografia e Navegação (DHN), e de dados obtidos junto ao banco de dados da empresa EnvEx Engenharia e Consultoria Ambiental (BRASIL, 2011).

Essa região estuarina recebe a drenagem de aproximadamente $70 \%$ da área da Bacia Hidrográfica Litorânea do Estado do Paraná (Bacia Atlântica). Especificamente para as Baías de Antonina e Paranaguá é drenada água doce de uma área de $2.188 \mathrm{~km}^{2}$, equivalente a $54 \%$

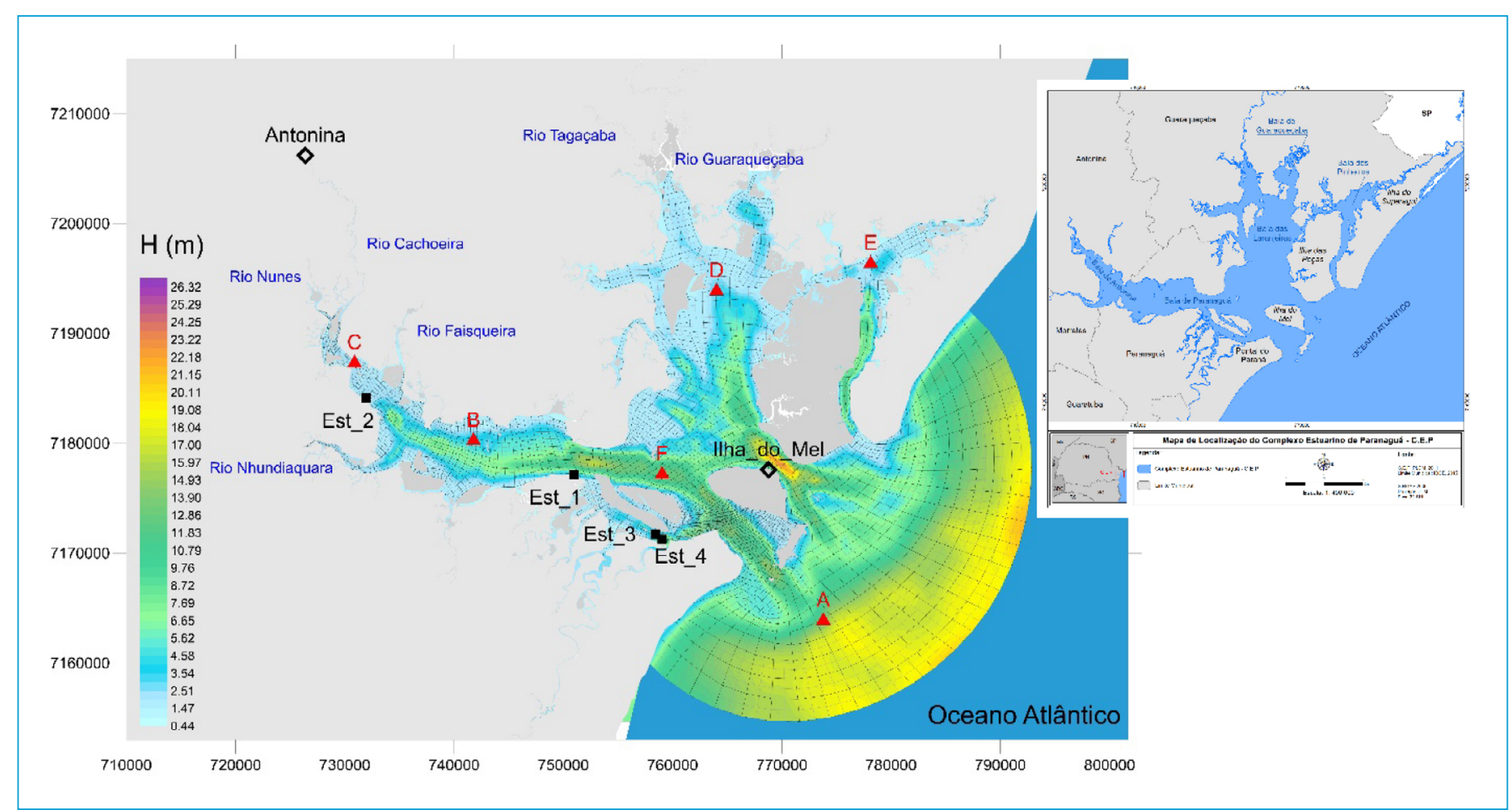

Figura 1 - Domínio de modelagem para o Complexo Estuarino de Paranaguá, mostrando a malha, a topografia de fundo em metros $(H)$ e a localização dos principais rios afluentes. Nas estações Est_3 e Est_4, dados de corrente e nível do mar, respectivamente, foram medidos no ano de 2009; no porto de Paranaguá (Est_1) e o no porto da Ponta do Félix (Est_2), dados de nível do mar foram medidos em 2011. Nas estações meteorológicas da llha do Mel e de Antonina foram medidos dados de vento. 
da área de drenagem do complexo. Nos meses mais chuvosos, entre janeiro e março, ocorre $40 \%$ do total anual da precipitação pluviométrica, e nos meses mais secos, entre junho e agosto, tem-se 15\% desse total (MANTOVANELLI et al., 2004).

O CEP tem um regime de marés semidiurno com amplitude média igual a 2,2 $\mathrm{m}$ em períodos de sizígia, caracterizado como mesomaré, enquanto as condições de micromaré podem ser observadas durante os períodos de quadratura (amplitude de maré entre 0,7 e 1,1 m) (LANA et al., 2001). As componentes mais importantes da maré astronômica são $\mathrm{M}_{2}$ e $\mathrm{S}_{2}$, que representam cerca de $50 \%$ da altura da maré (NOERNBERG et al., 2008).

Estudos prévios que enfocaram a circulação hidrodinâmica do CEP são limitados, podendo ser destacados o de: Mayerle et al. (2015), que usaram um modelo tridimensional para estudar o transporte de sedimentos coesivos baseado no sistema de modelagem Delft3D — os resultados obtidos pelo modelo foram comparados com dados medidos de concentração de sedimentos em suspensão, mostrando satisfatória concordância; e o de Mantovanelli et al. (2004), que caracterizaram a circulação e a dinâmica do sedimento em suspensão durante as estações chuvosas (verão) e secas (inverno) a partir de medições realizadas em uma seção próxima ao Porto de Paranaguá, mostrando que a maré é o principal forçante da circulação, seguida do aporte de água doce, e que o CEP muda a sua condição de estratificação: nas quadraturas de verão, apresenta-se altamente estratificado, passando a parcialmente misturado nas sizígias de verão e bem misturado durante as sizígias de inverno. É mostrada ainda a circulação residual induzida pela assimetria da onda de maré, causando diferenças nos tempos de enchente e vazante.

\section{Dados}

O domínio definido na modelagem é mostrado na Figura 1, em que também pode ser observada a malha de elementos finitos quadráticos, com 1.606 elementos finitos e 7.216 nós, usada na discretização do domínio e a localização dos principais rios. O SisBaHiA ${ }^{\circledR}$ define o coeficiente de atrito do fundo por meio do coeficiente de Chèzy, que depende da amplitude da rugosidade equivalente de fundo que, por sua vez, é definida a partir da composição e da distribuição de sedimentos no fundo. Os valores de amplitude de rugosidade do fundo

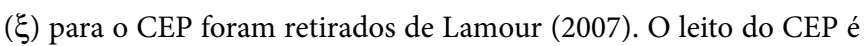
predominantemente composto por siltes $(\xi=0,001 \mathrm{~m})$, areias finas ( $\xi=0,015 \mathrm{~m}$ ) e médias ( $\xi=0,030 \mathrm{~m}$ ). Lamour (2007) observou um banco de areia predominantemente grossa $(\xi=0,050 \mathrm{~m})$ logo na saída do canal da Galheta.

\section{Calibração e validação}

Neste trabalho, um conjunto de dados obtidos no ano de 2009 foi usado para calibrar o modelo de circulação hidrodinâmica. No canal da Coatinga (indicado na Figura 1), entre os dias 24 de fevereiro de 2009 e 27 de março de 2009, foram feitas medições, com intervalos de 15 minutos, da posição da superfície livre (níveis de água); o local é identificado como estação Est_4. Medições de correntes foram realizadas entre os dias 04 e 07 de março de 2009 (período de quadratura) e entre os dias 11 e 14 de março de 2009 (período de sizígia); o local é identificado como estação Est_3. Para validar o modelo de circulação hidrodinâmica, foram usados os dados obtidos em 2011. Entre os dias 10 e 20 de julho de 2011 foi medida, próximo ao Porto de Paranaguá (Est_1) e ao Porto Ponta do Félix (Est_2), a posição da superfície livre. A localização das estações é mostrada na Figura 1.

A fim de calibrar o modelo de transporte euleriano, foi usada uma simulação da hidrodinâmica e do transporte de calor no CEP para os meses de janeiro, fevereiro e março de 2001. Os resultados obtidos com essa simulação foram comparados com valores de temperatura da água na estação F, obtidos por meio do convênio da Associação dos Portos de Paranaguá e Antonina (APPA) com o Centro de Estudos do Mar da Universidade Federal do Paraná (APPA; CEM, 2002). Para o balanço de calor, foram utilizados dados horários de radiação solar, temperatura e umidade relativa do ar, medidos na estação meteorológica instalada na cidade de Antonina para os meses de janeiro, fevereiro e março de 2001, obtidos junto ao Instituto Tecnológico SIMEPAR (Sistema Meteorológico do Paraná). A formulação do balanço de calor usada no SisBaHiA ${ }^{\circledR}$ é descrita em detalhes em Rosman (2017).

Para simular a hidrodinâmica nos períodos de 2001, 2009 e 2011, a maré astronômica foi obtida a partir de 11 constantes harmônicas definidas por Marone e Jamiyanaa (1997). Os dados de vazão fluvial, para os anos de 2001, 2009 e 2011, foram retirados do banco de dados Hidroweb, da Agência Nacional de Águas (ANA, 2017). As simulações realizadas entre os dias 24 e 27 de fevereiro de 2009, 4 e 7 de março de 2009 e $1^{\circ}$ e 14 de março de 2009 foram usadas na calibração do modelo, e entre os dias 10 e 20 de julho de 2011 foram usadas para validar o modelo. Nessas simulações foram usados dados de vento obtidos junto ao Instituto Tecnológico SIMEPAR, da estação meteorológica instalada na Ilha do Mel, com intensidade e direção dos ventos medidos a cada hora. Para o período de janeiro, fevereiro e março de 2001, os dados horários de direção e intensidade do vento foram medidos em uma estação localizada na cidade de Antonina (a localização é mostrada na Figura 1), também fornecidos pelo Instituto Tecnológico SIMEPAR. O campo de vento foi considerado homogêneo no espaço e variando ao longo do tempo. Nas simulações para os períodos de $1^{\circ}$ de janeiro de 2009 a 31 de março de 2009 e $1^{\circ}$ de junho de 2009 a 31 de agosto de 2009, usadas para o cálculo da TR, da IA e do escoamento residual, os dados sobre vento, característicos de verão e inverno, foram obtidos utilizando o modelo atmosférico Weather Research and Forecasting (WRF) (SKAMAROCK et al., 2008). 


\section{Cenários}

Para calcular a TR, IA e escoamento residual, seis cenários, mostrados na Tabela 1, foram considerados, para simular diferentes condições ambientais, o que viabiliza identificar quais forçantes - maré, vazão e vento - teriam maior influência na hidrodinâmica e, consequentemente, no processo de renovação das águas.

As vazões dos Rios Cachoeira, Nhundiaquara, Guaraqueçaba e Tagaçaba, utilizadas nos Cenários 3 a 6, consistem em uma média da série histórica (1994-2009) de dados de vazões diárias obtidos no portal Hidroweb. Já as vazões dos Rios Sagrado, Nunes e Faisqueira foram retiradas de Mantovanelli (1999). Foram consideradas as vazões dos meses de janeiro, fevereiro e março, para os Cenários 3 e 5 (verão), e dos meses de junho, julho e agosto, para os Cenários 4 e 6 (inverno).

Já os regimes de vento característicos de verão e inverno, utilizados nos seis cenários, foram obtidos utilizando o modelo atmosférico WRF (SKAMAROCK et al., 2008). O WRF utilizou como condições iniciais e de contorno dados do modelo operacional Global Forecast System (GFS) do National Centers for Environmental Prediction (NCEP) e dados do Projeto Reanalysis, coordenado pelo NCEP em conjunto com o National Center for Atmospheric Research (NCAR), que tem por objetivo produzir registros retroativos de análises globais de campos atmosféricos. Também foram utilizados dados de topografia e uso do solo do Serviço Geológico dos Estados Unidos (ARW, 2015), com detalhamento horizontal de $900 \times 900 \mathrm{~m}$, aproximadamente. Para que fosse possível analisar mais detalhadamente a região do CEP, foi realizada uma regionalização dinâmica, uma vez que os dados do Projeto Reanalysis são apresentados com um espaçamento de grade igual a $200 \mathrm{~km}$, aproximadamente, em 17 níveis na direção vertical e no intervalo temporal de seis horas.

$\mathrm{Na}$ regionalização dinâmica, a resolução da grade foi aumentada por meio da solução das equações do modelo em grades sucessivas, de resolução crescente, em que foram empregadas três grades aninhadas, com as seguintes configurações de espaçamento horizontal: grade externa $-100 \times 100 \mathrm{~km}$; grade intermediária $-25 \times 25 \mathrm{~km}$; grade interna $-5 \times 5 \mathrm{~km}$. Foram utilizados 50 níveis verticais, sendo que

Tabela 1 - Características dos seis cenários usados para definir a circulação hidrodinâmica e as taxas de renovação, idade da água e escoamento residual no complexo estuarino de Paranaguá.

\begin{tabular}{|c|c|c|c|}
\hline Cenários & Forçantes & Estação & Período de simulação \\
\hline Cenário 1 & Maré & Verão & 10/1/2009 a 31/3/2009 \\
\hline Cenário 2 & Maré & Inverno & 10/6/2009 a 31/8/2009 \\
\hline Cenário 3 & Maré e vazão fluvial & Verão & 10/1/2009 a 31/3/2009 \\
\hline Cenário 4 & Maré e vazão fluvial & Inverno & 10/6/2009 a 31/8/2009 \\
\hline Cenário 5 & $\begin{array}{c}\text { Maré, vazão fluvial } \\
\text { e vento }\end{array}$ & Verão & 10/1/2009 a 31/3/2009 \\
\hline Cenário 6 & $\begin{array}{c}\text { Maré, vazão fluvial } \\
\text { e vento }\end{array}$ & Inverno & 10/6/2009 a 31/8/2009 \\
\hline
\end{tabular}

o primeiro nível acima da superfície estava a cerca de $20 \mathrm{~m}$ de altura, de forma a permitir uma representação adequada da camada limite superficial atmosférica.

As simulações ocorreram de forma bidirecional, ou seja, os valores calculados na grade maior foram utilizados como condição de contorno na grade menor e, posteriormente, os pontos da grade maior receberam o valor médio dos pontos da grade menor (CARVALHO, 2015). Com as simulações na grade interna (espaçamento de $5 \times 5 \mathrm{~km}$ ) foram gerados 150 pontos (estações) na região do CEP, sendo possível obter dados horários de intensidade e direção do vento a $10 \mathrm{~m}$ da superfície, para cada uma dessas 150 estações.

\section{Sobre os modelos usados}

O sistema de modelagem usado neste trabalho é o Sistema Base de Hidrodinâmica Ambiental ( $\mathrm{SisBaHiA}^{\circledR}$ ), desenvolvido pelo Instituto Alberto Luiz Coimbra de Pós-Graduação e Pesquisa de Engenharia da Universidade Federal do Rio de Janeiro (COPPE/UFRJ). As simulações computacionais deste estudo foram realizadas utilizando o modelo hidrodinâmico bidimensional e o modelo de transporte euleriano do SisBaHiA ${ }^{\circledR}$. O modelo hidrodinâmico utiliza um esquema numérico implícito de segunda ordem, para a discretização temporal, e elementos finitos quadráticos, para a discretização espacial. O modelo de transporte euleriano utiliza a mesma discretização espacial e o mesmo esquema para discretização temporal do modelo hidrodinâmico (ROSMAN, 2017).

Primeiramente, foi realizada a calibração e validação do modelo hidrodinâmico e, posteriormente, a calibração do modelo de transporte euleriano. Em seguida, o modelo de transporte euleriano, utilizado para analisar a renovação das águas do sistema, foi usado para diferentes cenários hidrodinâmicos.

\section{Indicadores de renovação}

Neste trabalho, a quantificação da renovação das águas foi feita a partir de três indicadores: TR, IA e escoamento residual. A TR pode ser considerada como a taxa de troca de água dentro de um determinado volume de controle, que informa o quanto (\%) desse volume de água foi renovado. Sendo assim, as TRs foram calculadas simulando o transporte de um constituinte conservativo ao longo do domínio pelos processos de advecção e difusão. No instante inicial foi atribuída uma concentração desse constituinte igual a zero a toda a água dentro do domínio de interesse, ou seja, atribuiu-se a essa água um índice de renovação de $0 \%$. Já para as águas que entram no domínio pelos afluentes e pela fronteira aberta foram atribuídos valores de concentração iguais a 100, o que equivale a um índice de renovação de 100\%. Assim, conforme as águas iniciais (com índice $0 \%$ ) forem se misturando com as águas novas afluentes (com índice 100\%) e a mistura for sendo expelida do domínio, as águas serão renovadas (DALAZEN, 2017). 
A IA de uma determinada parcela pode ser definida como o tempo que passou desde a entrada dessa parcela no domínio (ZIMMERMAN; KJERFVE, 1988). Mais recentemente, outra definição desse parâmetro foi desenvolvida por Delhez (2006), na qual se distingue a IA pura da idade de constituintes presentes na água (sais, poluentes etc.); assim, a IA é definida como o tempo gasto para que esses constituintes deixem a região de interesse. Neste trabalho, o tempo de decaimento de uma substância passiva marcadora de idade presente na água é calculado como a IA. Para que isso seja possível, é necessário que essa substância marcadora tenha reação cinética de decaimento de primeira ordem com uma taxa de decaimento constante e positiva, não sendo considerados outros efeitos de perda ou de ganho de massa. Assim, admite-se que, no instante inicial, a concentração dessa substância é igual a 1,0 em todo o domínio. Consequentemente, a IA é nula. De forma análoga ao modelo anterior, as águas afluentes tinham concentrações iguais a 1,0 e IA $=0$. À medida que as águas iniciais e as águas novas, ambas com $\mathrm{IA}=0$, foram se misturando e sendo transportadas no domínio, a concentração da substância vai diminuindo devido ao processo de decaimento e, por consequência, o valor de IA irá se tornar diferente em cada ponto.

A propagação da onda dentro de um estuário depende das características topográficas do local e dos efeitos que ela sofre devido ao atrito com as margens e o fundo (DYER, 1973). Esses efeitos provocados pelo atrito, pelo vento e pela entrada de água doce dos rios provocam interações não lineares que geram correntes aperiódicas, conhecidas como correntes residuais (XU; MAO; JIANG, 2016). Essas correntes residuais têm um papel importante no estudo da renovação das águas de corpos estuarinos, pois controlam a importação e exportação de constituintes nesses locais, representando as mudanças na duração dos períodos de enchente e vazante que, por sua vez, podem propiciar a definição das áreas de estagnação. Neste trabalho, as correntes residuais foram calculadas para um referencial euleriano, com um período de 25 horas.

\section{RESULTADOS E DISCUSSÃO}

\section{Calibração e validação dos modelos}

Foram simulados três períodos: os anos de 2001, 2009 e 2011. O conjunto de dados de 2009 foi usado para calibrar o modelo de circulação hidrodinâmica; o de 2011, para validação; e o de 2001, para verificação do modelo de transporte. Em todas as simulações da circulação hidrodinâmica utilizou-se o modelo hidrodinâmico bidimensional em planta do SisBaHiA ${ }^{\circledR}$, com um passo de tempo $\Delta \mathrm{t}=20,0 \mathrm{~s}$, gerando um número de Courant máximo de 5,9 e médio de 0,7. A Figura 2 mostra a comparação entre séries temporais da posição da superfície livre obtidas pelo SisBaHiA ${ }^{\circledR}$ e os valores medidos na estação Est_4 (localização indicada na Figura 1) nos períodos de quadratura (28 de fevereiro de 2009 a 7 de março de 2009) e sizígia (8 a 16 de março 2009). Observa-se que houve boa concordância em relação à fase, porém diferenças de amplitude podem ser observadas. Isso pode ser explicado pelo fato de

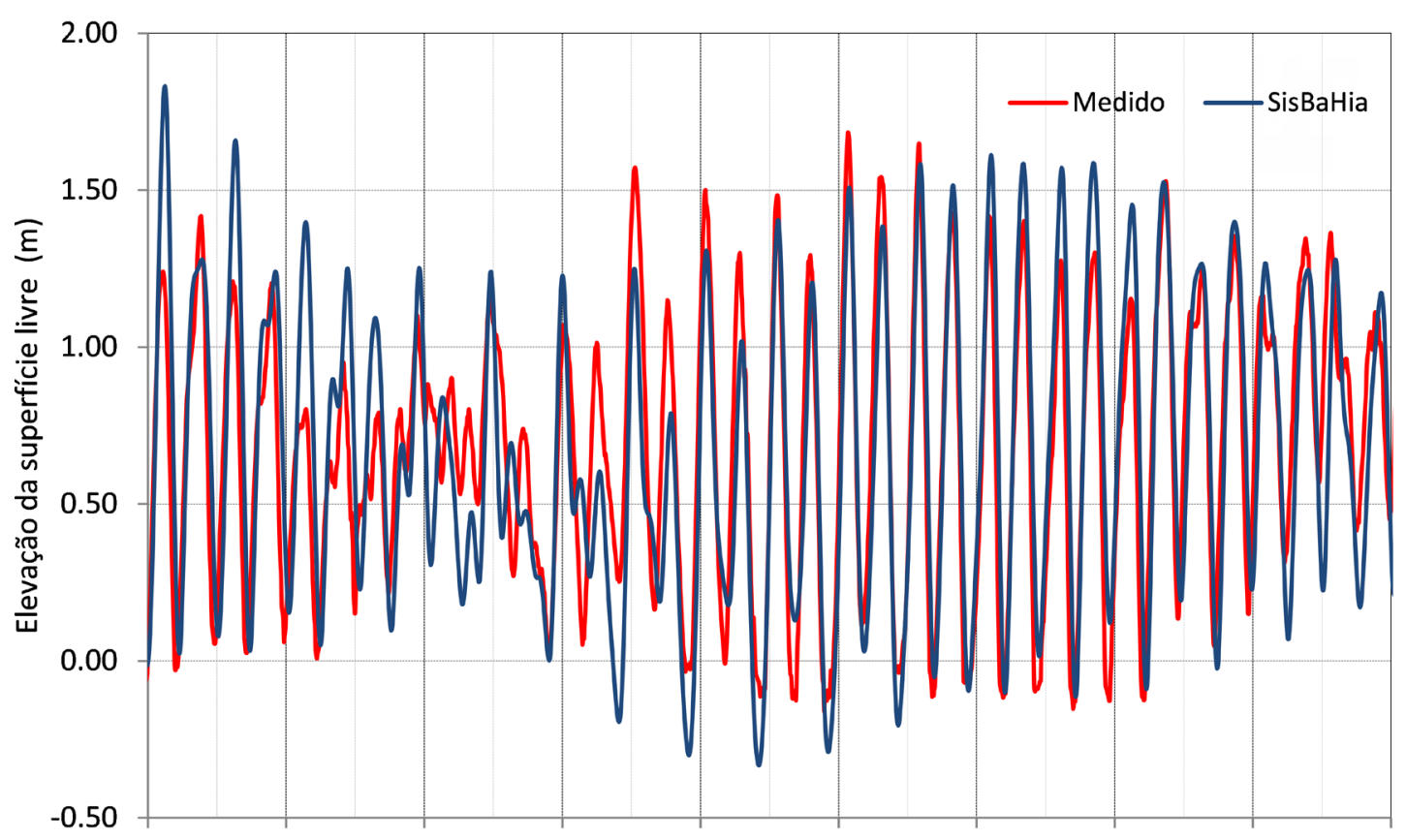

28/02/09 02/03/09 04/03/09 06/03/09 08/03/09 10/03/09 12/03/09 14/03/09 16/03/09 18/03/09

Figura 2 - Elevação da superfície livre obtida pelo SisBaHiA ${ }^{\circledast}$ e os dados medidos (Est_4), nos períodos de quadratura (28 de fevereiro de 2009 a 7 de março de 2009) e sizígia ( 8 a 16 de março de 2009). 
a estação Est_4 estar localizada em uma região rasa, com as maiores diferenças acontecendo no período de quadratura. No período de sizígia também se nota boa concordância em relação à fase. Rosman (2017) observa que os valores de elevação da superfície livre estarão calibrados se os erros forem inferiores a $5 \%$.

As maiores diferenças acontecem na preamar e na baixa-mar, nos demais instantes os erros apresentam valores satisfatórios. Entre os dias 14 e 18 de março, observam-se intensificação das diferenças e elevação do nível médio medido de cerca de $30 \mathrm{~cm}$; variações de nível médio podem estar relacionadas à presença de evento meteorológico. O erro médio no período de quadratura para a posição da superfície livre foi de $12 \%$; no período da sizígia, o erro médio foi de $10 \%$; considerando-se apenas o período entre os dias 8 e 14 de março, sem contabilizar a possível ocorrência do evento meteorológico, o erro médio observado foi de $4 \%$.

Observando-se a localização da estação onde foram feitas as medições, na parte mais interna da Baía de Paranaguá, em um canal raso e estreito, os valores da componente leste-oeste das velocidades de corrente são mais significativos que a componente norte-sul, em função do alinhamento do canal. Sendo assim, apenas a comparação entre a componente leste-oeste das velocidades de correntes obtidas pelo SisBaHiA ${ }^{\circledR}$ e os valores medidos na estação Est_3 é mostrada (Figura 3). Com o objetivo de mostrar o padrão de escoamento local, a Figura 3 também mostra os diagramas de dispersão das componentes das velocidades de correntes medidas e obtidas pelo SisBaHiA ${ }^{\oplus}$. Os resultados representam dois períodos, entre os dias 4 de março de 2009 e 7 de março de 2009, no período de quadratura, e entre 11 de março de 2009 e 14 de março de 2009, no período de sizígia.

Comparando-se as séries temporais entre os dados medidos e os resultados calculados pelo SisBaHiA ${ }^{\circledR}$, nota-se boa concordância de fase entre os resultados. No que se refere à intensidade de corrente, há atenuação nos valores obtidos pelo SisBaHiA ${ }^{\circledR}$ em relação aos valores medidos. Observando-se os diagramas de dispersão, os resultados obtidos pelo SisBaHiA ${ }^{\circledR}$ apresentam-se menos dispersos do que os

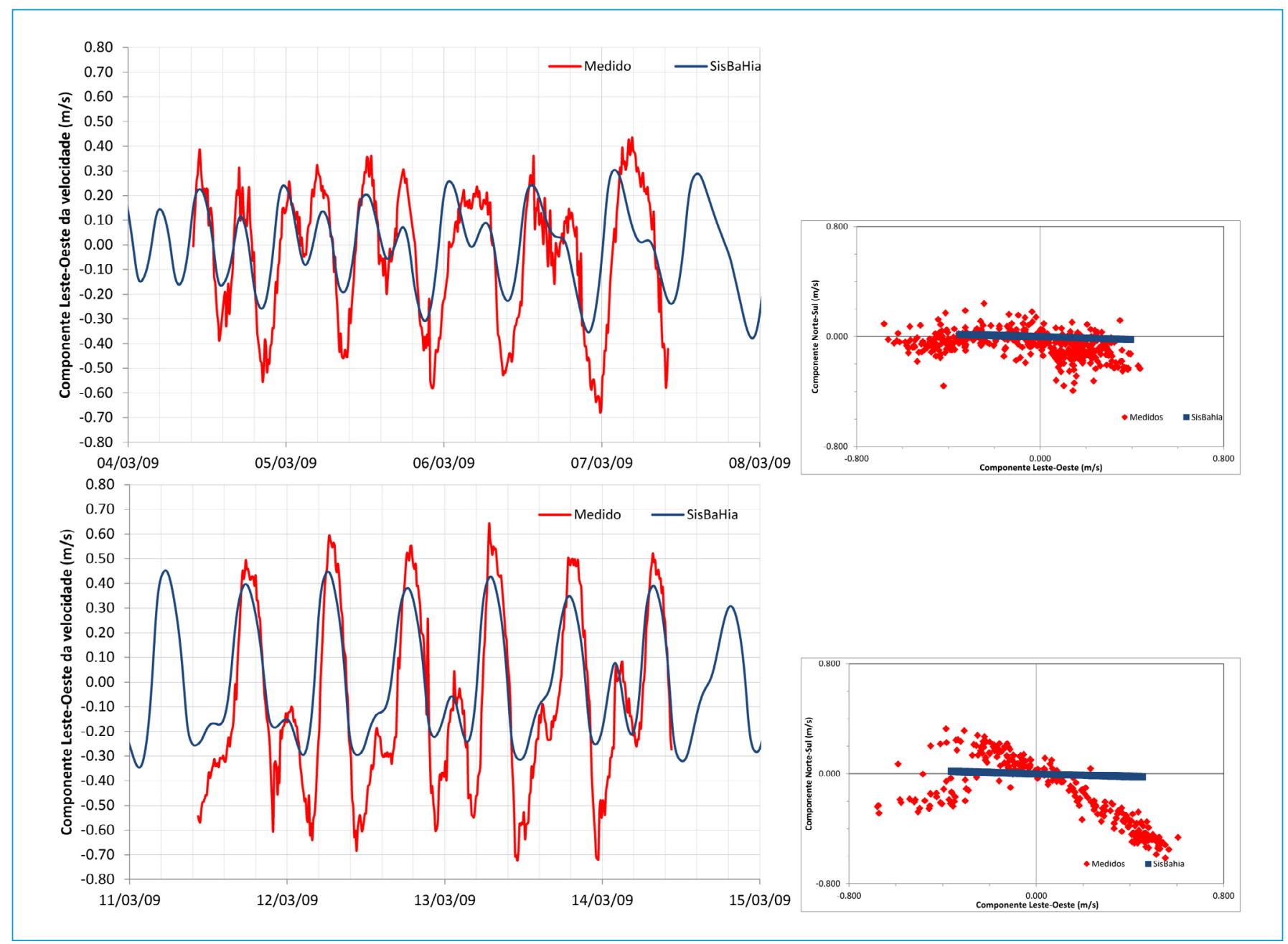

Figura 3 - Componente Leste-Oeste das velocidades de corrente $(\mathrm{m} / \mathrm{s})$ obtidas pelo SisBaHiA ${ }^{\circledR}$ comparada com os valores medidos (Est 3 ) e os diagramas de dispersão das componentes das velocidades de correntes medidas e obtidas pelo SisBaHiA ${ }^{\oplus}$, entre 4 e 8 de março de 2009 e 11 e 15 de março de 2009. 
valores medidos, e no período de sizígia ocorre inversão no sentido da componente norte-sul das velocidades de corrente medida, não observada nos resultados obtidos pelo SisBaHiA ${ }^{\circledR}$. Como a estação onde os dados foram medidos está localizada um canal raso e estreito, onde a batimetria e a largura do canal principal são muito irregulares, desvios na direção e no sentido das correntes podem ser provocados pela suavização da topografia de fundo realizada pelo modelo e, ainda, por pequenas irregularidades locais na topografia de fundo que não são possíveis de serem representadas no modelo. Sendo assim, as velocidades de corrente apresentam-se bastante variáveis no espaço e uma pequena diferença de posição pode significar grandes mudanças nos valores de velocidade. Para obter melhor aproximação com os dados de campo, seria necessário refinar a malha nessa região, para obter a resolução necessária para a distribuição de velocidades.

Entre os dias 10 e 20 de julho de 2011, próximo ao porto da Ponta do Félix (Est_2) e do Porto de Paranaguá (Est_1), foram realizadas medições da elevação da superfície livre e os valores foram comparados com os valores obtidos com o SisBaHiA ${ }^{\circledR}$, a fim de validar o modelo de circulação hidrodinâmica. Os resultados obtidos pelo SisBaHiA ${ }^{\circledR}$ apresentaram boa concordância em relação à fase e à amplitude (Figura 4). As maiores diferenças ocorreram na preamar e na baixa-mar; a média do erro na região próxima ao Porto da Ponta do Félix foi de 8,5\% e próximo ao Porto de Paranaguá, de 7\%.

$\mathrm{Na}$ Figura 5 são apresentados os padrões espaciais de velocidade, no período de sizígia, nos instantes de meia-maré enchente (21 de junho de 2009 às 13h) e meia-maré vazante (20 de junho de 2009 às $17 \mathrm{~h})$, respectivamente, no $\mathrm{CEP}$, com destaque para a região da Baía de Paranaguá. Nos campos de velocidades apresentados, verifica-se forte relação com a batimetria. Nos dois períodos é possível observar intensificação das correntes nos locais de estrangulamento devido à diminuição da área e da influência da orientação dos canais.

No período de 23 de janeiro de 2001 a 31 de março de 2001, valores de temperatura foram medidos na estação F, cuja localização está indicada na Figura 1, e comparados com os fornecidos pelo SisBaHiA ${ }^{\circledR}$.

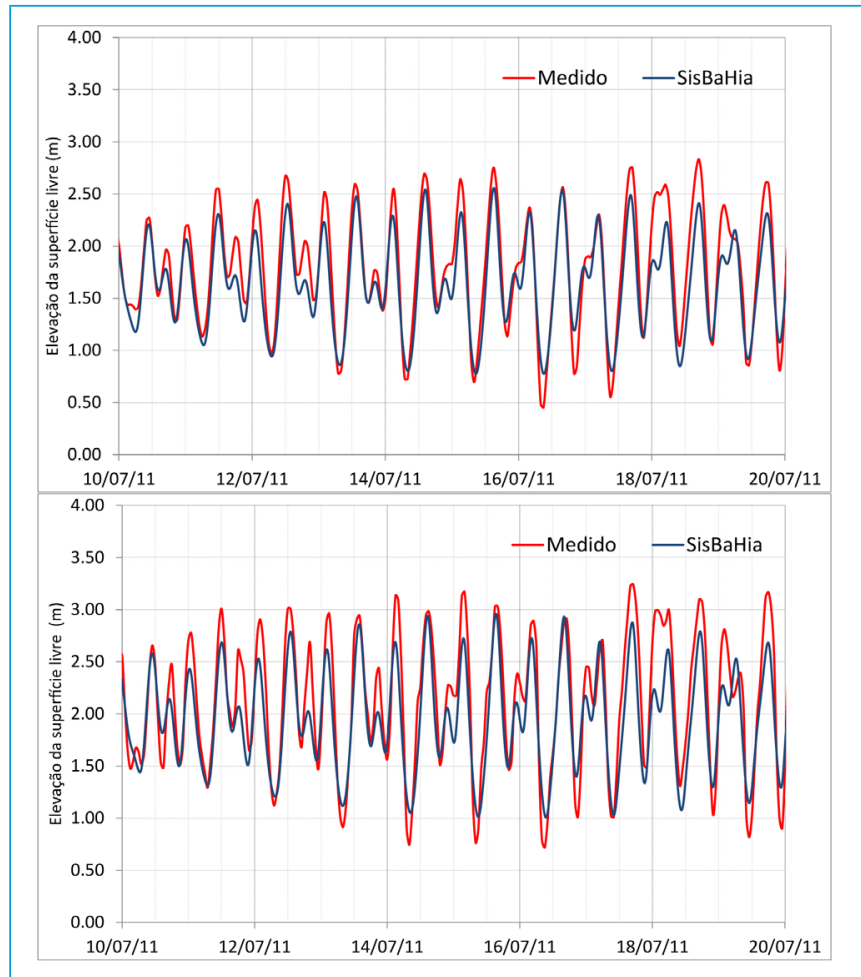

Figura 4-Elevação da superfície livre, em metros, obtida pelo SisBAHIA ${ }^{\oplus}$, e os dados medidos, próximo ao Porto de Paranaguá, Est_1 (esquerda) e Porto da Ponta do Félix, Est_2 (direita) entre 10 e 20 de julho de 2011.

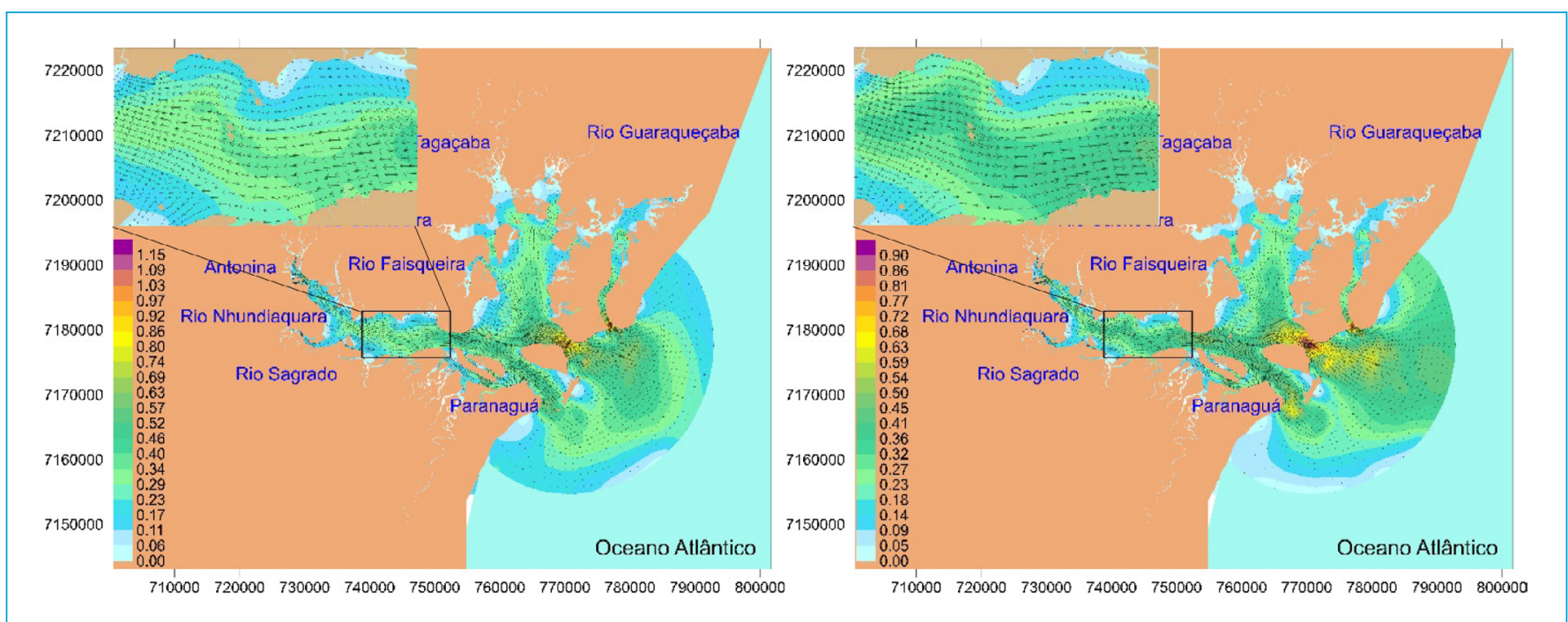

Figura 5 - Campos de corrente (m/s) no domínio do modelo no instante de meia-maré enchente, 21 de junho de 2009 às $13 \mathrm{~h}$ (esquerda), e no instante de meia maré vazante, 20 de junho de 2009 às 17h (direita), no período de sizígia, com destaque para a região da baía de Paranaguá. 
O modelo de transporte usa a mesma malha em elementos finitos do modelo hidrodinâmico, além de importar o campo de velocidades. Sendo assim, foi previamente simulada a hidrodinâmica nesse período. O passo de tempo adotado nas simulações de transporte foi de 100,0 s. Os coeficientes de dispersão horizontal foram ajustados com os seguintes valores: $\mathrm{D}_{\mathrm{xx}}=5,0 \mathrm{~m}^{2} / \mathrm{s} \mathrm{e}_{\mathrm{yy}}=5,0 \mathrm{~m}^{2} / \mathrm{s}$. Foram prescritas as seguintes condições de contorno: $25^{\circ} \mathrm{C}$, para afluxo por meio da fronteira aberta, e $23^{\circ} \mathrm{C}$, para afluxo fluvial (SILVEIRA et al., 2012). O modelo foi simulado entre $1^{\circ}$ de janeiro de 2001 e 31 de março de 2001. Como condição inicial foi considerada a temperatura de $25^{\circ} \mathrm{C}$ para todo o domínio; a comparação com os dados medidos só ocorreu a partir do dia 23 de janeiro de 2001, tempo necessário para que o modelo produzisse resultados confiáveis.

Segundo Rosman (2017), deve-se esperar do modelo de transporte concordância entre os valores medidos e os valores calculados semelhante à verificada no modelo hidrodinâmico, visto que o modelo de transporte recebe como dados de entrada os resultados obtidos com o modelo hidrodinâmico e, portanto, a confiabilidade dos resultados gerados pelo modelo de transporte está relacionada com a qualidade dos resultados hidrodinâmicos. Os erros relativos gerados pelo modelo de transporte não ultrapassam os $15 \%$, produzindo erro médio em torno de $4 \%$.

\section{Taxas de renovação}

As TRs em baías e estuários indicam as diferenças encontradas em relação à capacidade de troca em seus diversos compartimentos, sendo possível observar as variações espaciais e temporais em relação aos forçantes e a sua morfologia. Nesse sentido, foram estabelecidas seis estações designadas A, B, C, D, E e F, cujas localizações, mostradas na Figura 1, caracterizam os diferentes compartimentos do CEP.

A Figura 6 apresenta as evoluções temporais da TR nas estações A, B, C, D, E e F, para os Cenários 1, 3 e 5 (cenários de verão), durante três meses de simulação. Observa-se que, entre todas as estações, as águas são renovadas mais lentamente no Cenário 1 , no qual o único afluxo de água "nova" é pela fronteira aberta. Essa diferença é menor na estação A, considerando-se que está localizada mais próxima da fronteira aberta, com pouca influência das vazões fluviais. Considerando-se os Cenários 3 e 5, é possível observar que a vazão fluvial é um forçante importante no processo de renovação nas regiões próximas aos afluentes, visto que a sua inclusão promove significativo aumento das taxas de renovação, quando comparado com o Cenário 1, que considera somente a maré. Além disso, as diferenças entre as TRs sem vento (Cenário 3) e com vento (Cenário 5) são mínimas, o que mostra a pouca influência do vento sobre o processo de renovação das águas do CEP, quando comparado com as vazões fluviais.

$\mathrm{Na}$ estação $\mathrm{C}$, as diferenças entre os Cenários 3 e 5 são muito pequenas, pois essa estação é a que se localiza mais próxima da foz dos principais rios do CEP, o que torna a ação do vento irrelevante, quando comparada com a da vazão fluvial. Nas estações D, E e F, nota-se que o vento provoca ligeira desaceleração no processo de renovação, o que pode indicar o empilhamento da água dentro do estuário. Observa-se ainda que a região da Baía dos Pinheiros (estação E) e a região próxima à cidade de Paranaguá (estação F) apresentam processos de renovação mais lentos do que as demais áreas, condição que é ligeiramente acentuada com a inclusão do vento, o que indica a possibilidade de essas áreas estarem sob o efeito de empilhamento causado pelo vento.

A Figura 7 apresenta a evolução temporal da TR nas seis estações para os Cenários 2, 4 e 6, que corresponderam aos cenários de inverno, durante três meses de simulação. Assim como nos cenários representativos de verão, as águas são renovadas mais lentamente no cenário em que apenas a maré é o forçante. Apesar de as diferenças entre os Cenários 2 e 4 serem menores do que as diferenças entre os Cenários 1 e 3 , o que acontece devido às vazões fluviais serem significativamente menores no inverno do que no verão, pode-se afirmar que a vazão fluvial continua sendo um forçante de grande importância no processo de renovação das águas. Também é possível observar que as diferenças entre os Cenários 4 e 6 são menores do que as diferenças entre os Cenários 3 e 5. Isso ocorre porque o Cenário 6 tem um regime de vento menos intenso do que o Cenário 5, o que atenua ainda mais a influência do vento na renovação das águas no CEP.

Observando-se os resultados obtidos pelo $\mathrm{SisBaHiA}^{\circledR}$ para a distribuição espacial das TRs para todo o domínio do CEP, após 90 dias de simulação (Figura 8), é possível concluir que existem duas áreas com as menores taxas de renovação: a região da Baía dos Pinheiros, próxima à estação $\mathrm{E}$, e a região em frente à cidade de Paranaguá, entre as estações F e B. Esse comportamento pode ser observado para o Cenário 5, com maré, vento e vazão fluvial durante o verão, quando as TRs nessas regiões são menores que 95\%; nas demais regiões do CEP, os valores são superiores a 95\%. Considerando-se apenas a maré, Cenário 1, a região com menores TRs migra para a foz dos Rios Cachoeira e Nunes (estação C); a região da Baía de Antonina apresenta TR menor que 40\%. Nesse sentido, é possível afirmar que a vazão fluvial tem papel importante como forçante para garantir a renovação nas regiões próximas aos afluentes e, ainda, que essas duas regiões, a Baía dos Pinheiros e a região próxima à cidade de Paranaguá, são, possivelmente, áreas propensas à estagnação.

\section{Idade da água}

A Figura 9 apresenta a distribuição espacial da IA para todo o domínio do CEP nos Cenários 1 e 5, após 90 dias de simulação. Considerando-se que a diferença entre a distribuição espacial da IA entre os Cenários 3 (sem vento) e 5 (com vento) é mínima, optou-se por não exibir o resultado do Cenário 3. 


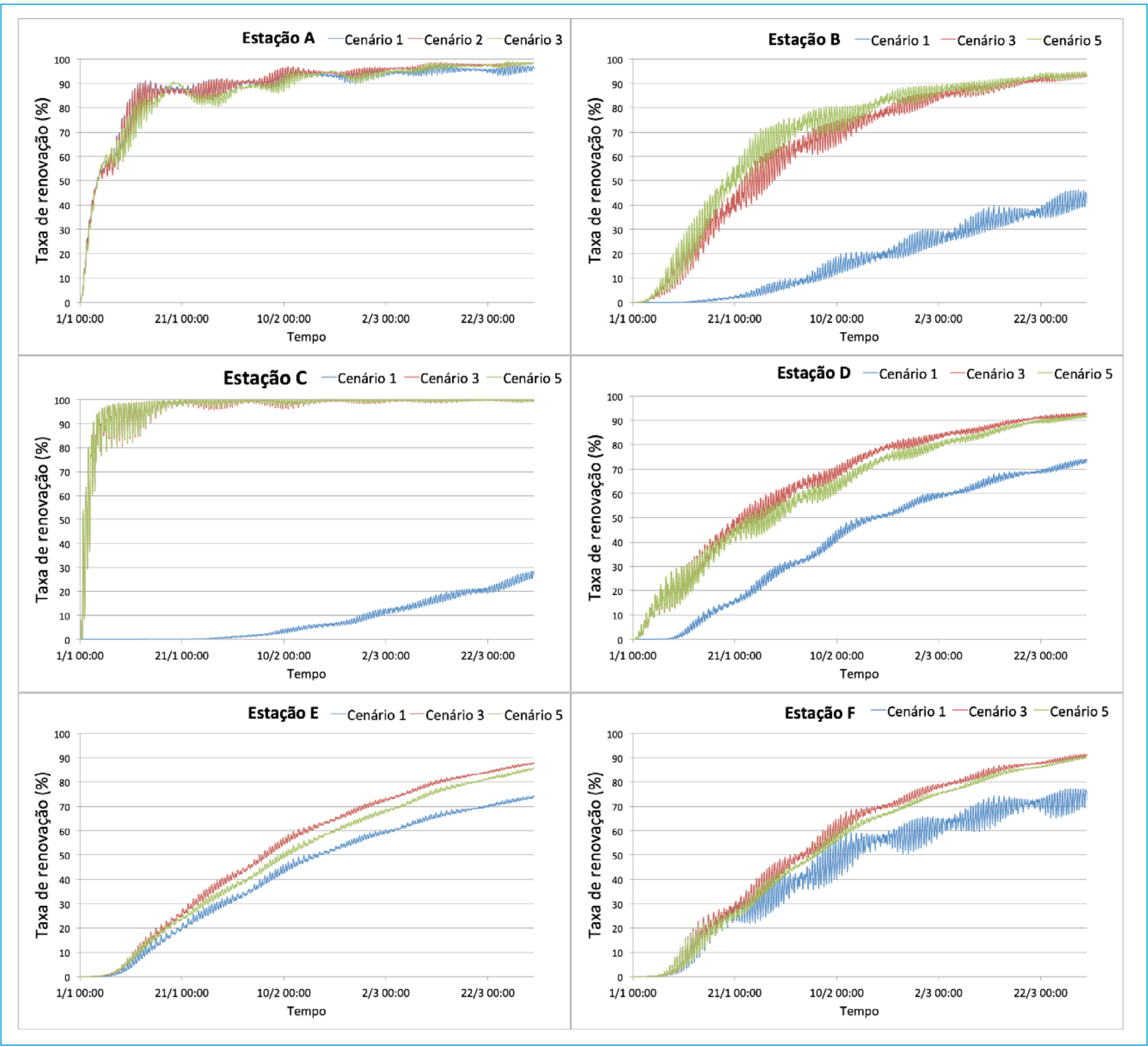

Figura 6 - Evolução temporal das taxas de renovação (\%) para os cenários 1 (maré), 3 (maré e vazão) e 5 (maré, vazão e vento) nas estações A, B, C, $\mathrm{D}, \mathrm{E}$ e F durante o verão.

É possível observar que as águas apresentam idades maiores no Cenário 1, ou seja, ficam mais tempo sem serem renovadas. Assim como constatado nos resultados das taxas de renovação, é possível observar que as vazões fluviais influenciam mais diretamente o processo de troca das águas nas estações B, C e D, que representam o compartimento mais interno do CEP. Já nas demais estações a diferença na evolução temporal da IA entre os cenários é mínima, indicando que a inclusão das vazões fluviais e do vento não causa grandes diferenças no processo de renovação das águas dessas regiões. Durante o verão e considerando-se todos os forçantes (Cenário 5), as idades da água na região da Baía dos Pinheiros e na região próxima à cidade de Paranaguá são maiores que 25 dias; nas demais regiões do CEP, os valores são inferiores 10 dias.

A Tabela 2 apresenta um resumo dos valores de TR e dos valores de IA após 90 dias de simulação, para todas as estações e cenários. Nota-se significativa melhora no processo de renovação das águas quando são incluídas as vazões fluviais (Cenários 3, 4, 5 e 6), principalmente nas estações B e C. A inclusão do vento (Cenários 5 e 6) causa leve diminuição nas TRs (e aumento da IA) na maioria das estações, não implicando grandes diferenças. Na estação $\mathrm{A}$, os valores, tanto para 


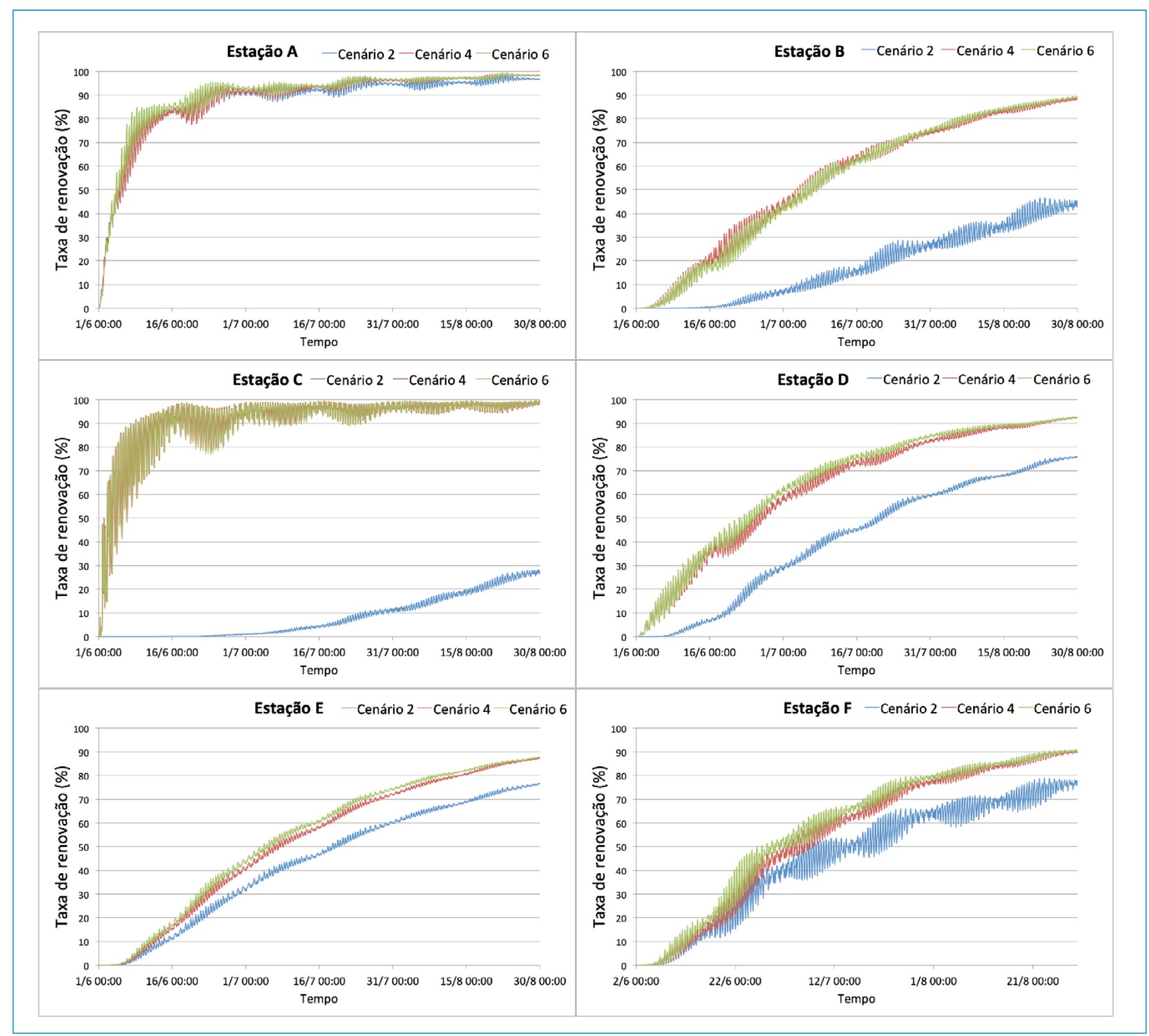

Figura 7 - Evolução temporal das taxas de renovação (\%) para os cenários 2 (maré), 4 (maré e vazão) e 6 (maré, vazão e vento) nas estações A, B, C, $D, E$ e $F$ durante o inverno.

a TR como para a IA, são praticamente iguais para todos os cenários. Nota-se também que os valores de TR e IA dos períodos representativos de verão e inverno são bastante semelhantes para cada um dos cenários, sendo que, no verão, as TRs são maiores.

É importante ressaltar que a posição da fronteira aberta influencia diretamente os resultados obtidos de TR e IA. Isso ocorre porque quanto mais próxima à fronteira aberta estiver da desembocadura da região estuarina, a TR por causa da maré, calculada dentro do CEP, será ainda mais intensa. De modo semelhante, as regiões próximas aos rios teriam TRs menores se os limites do domínio fossem alterados, estendendo para montante.

\section{Escoamento residual}

Os campos de velocidades residuais foram calculados para um referencial euleriano, considerando um período de sizígia, com período de aproximadamente 25 horas. A Figura 10 apresenta o campo de correntes residuais para os Cenários 3 e 4, com os forçantes maré e vazão, nos períodos de verão e inverno, respectivamente. A intensidade do escoamento residual é significativamente diferente para o verão e o inverno, aumentando de forma bastante importante no verão, principalmente em decorrência das elevadas vazões fluviais. É possível ainda confirmar a formação de possíveis áreas de estagnação, na região da Baía dos Pinheiros e na região próxima à cidade de Paranaguá, que têm 


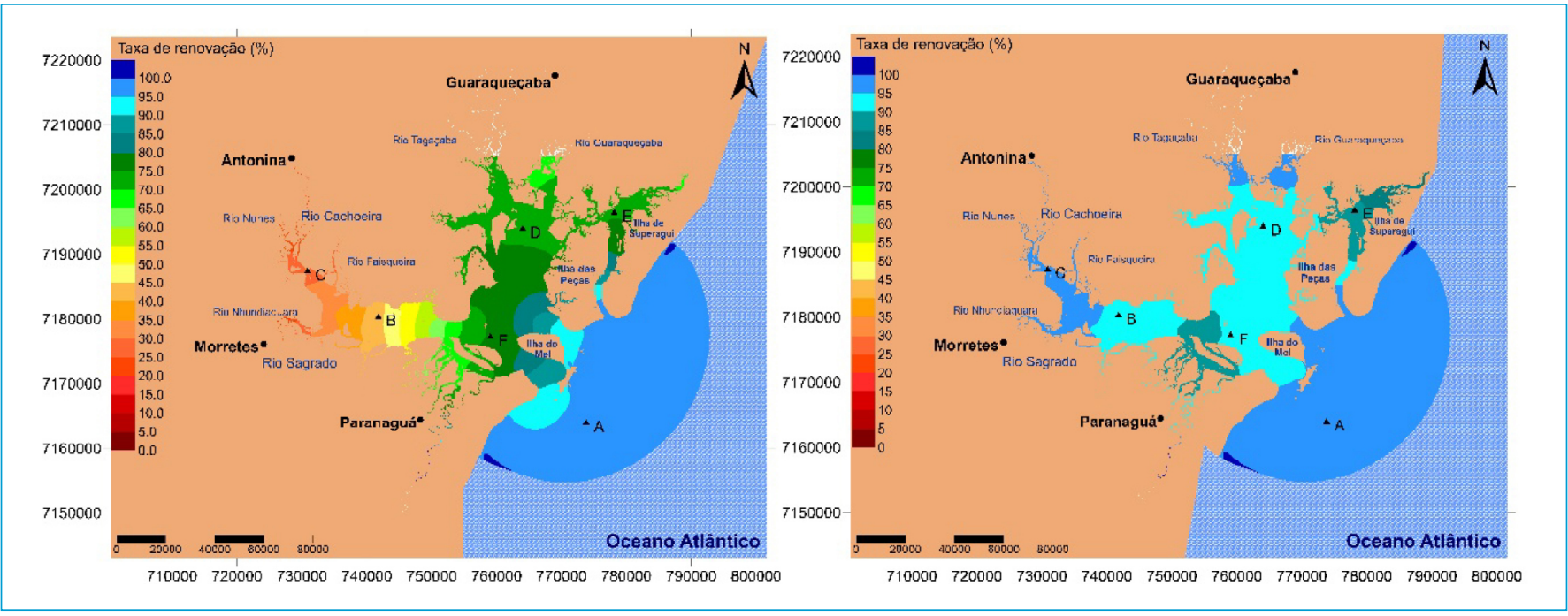

Figura 8 - Taxas de renovação (\%) para todo o domínio do complexo estuarino de Paranaguá após 90 dias de simulação nos cenários 1 , maré (esquerda) e 5, maré, vazão e vento (direita).

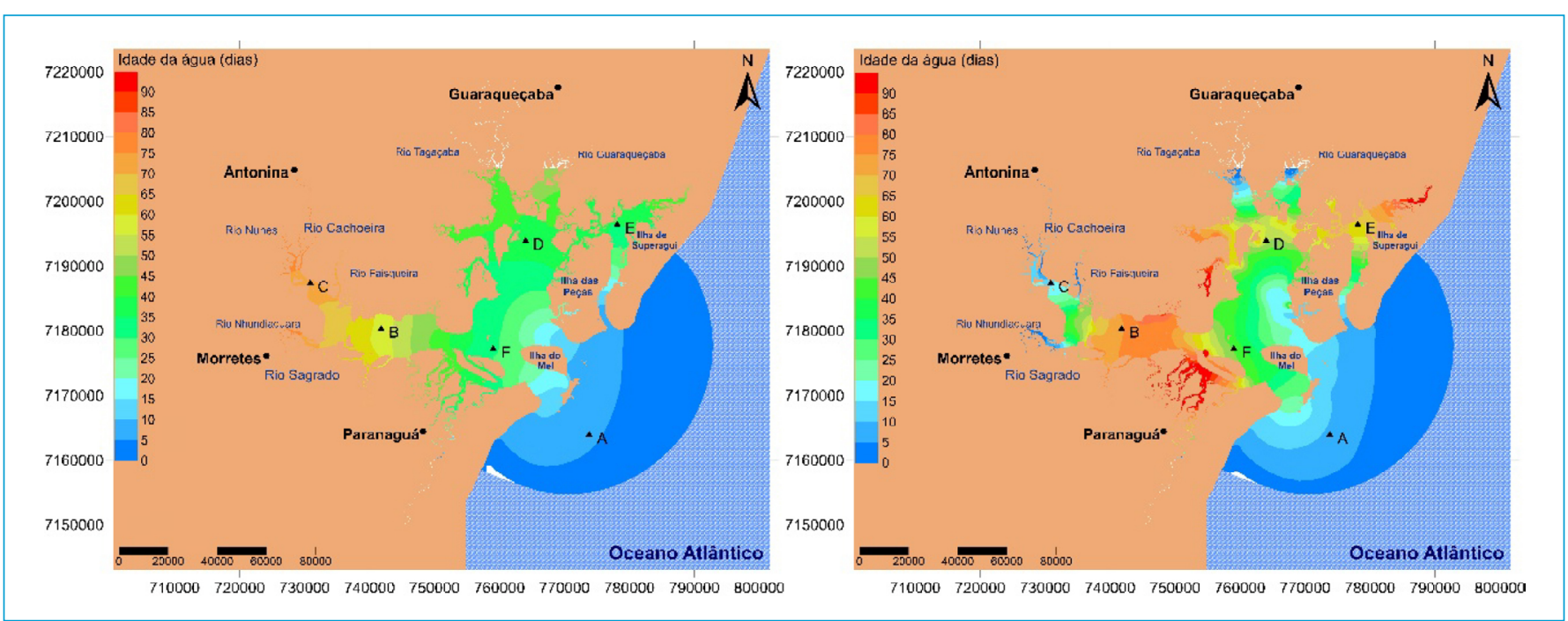

Figura 9 - Idade da água, em dias, para todo o domínio do complexo estuarino de Paranaguá após 90 dias de simulação nos cenários 1 , maré (esquerda) e 5, maré, vazão e vento (direita).

Tabela 2 - Valores de taxa de renovação, em \%, e idade da água, em dias, para todos os cenários nas estações A, B, C, D, E e F, após 90 dias de simulação.

\begin{tabular}{l|c|c|c|c|c|c|c|c|c|c|c|c|} 
Cenários & \multicolumn{2}{|c|}{1} & \multicolumn{2}{|c|}{2} & \multicolumn{2}{c|}{3} & \multicolumn{2}{c}{5} & \multicolumn{2}{c}{5} \\
\hline Estação & TR & IA & TR & IA & TR & IA & TR & IA & TR & IA & TR & IA \\
\hline A & $97 \%$ & 6 & $97 \%$ & 6 & $99 \%$ & 6 & $98 \%$ & 6 & $98 \%$ & 6 & $98 \%$ & 7 \\
\hline B & $43 \%$ & 58 & $45 \%$ & 56 & $93 \%$ & 22 & $88 \%$ & 30 & $94 \%$ & 25 & $89 \%$ & 29 \\
\hline C & $28 \%$ & 73 & $28 \%$ & 73 & $100 \%$ & 3 & $98 \%$ & 6 & $100 \%$ & 4 & $99 \%$ & 5 \\
\hline D & $74 \%$ & 38 & $76 \%$ & 35 & $93 \%$ & 21 & $92 \%$ & 20 & $92 \%$ & 25 & $92 \%$ & 22 \\
\hline E & $75 \%$ & 35 & $77 \%$ & 33 & $88 \%$ & 28 & $87 \%$ & 29 & $86 \%$ & 34 & $88 \%$ & 31 \\
\hline F & $75 \%$ & 31 & $78 \%$ & 29 & $91 \%$ & 27 & $90 \%$ & 27 & $90 \%$ & 31 & $91 \%$ & 28 \\
\hline
\end{tabular}

TR: taxa de renovação; IA: idade da água. 


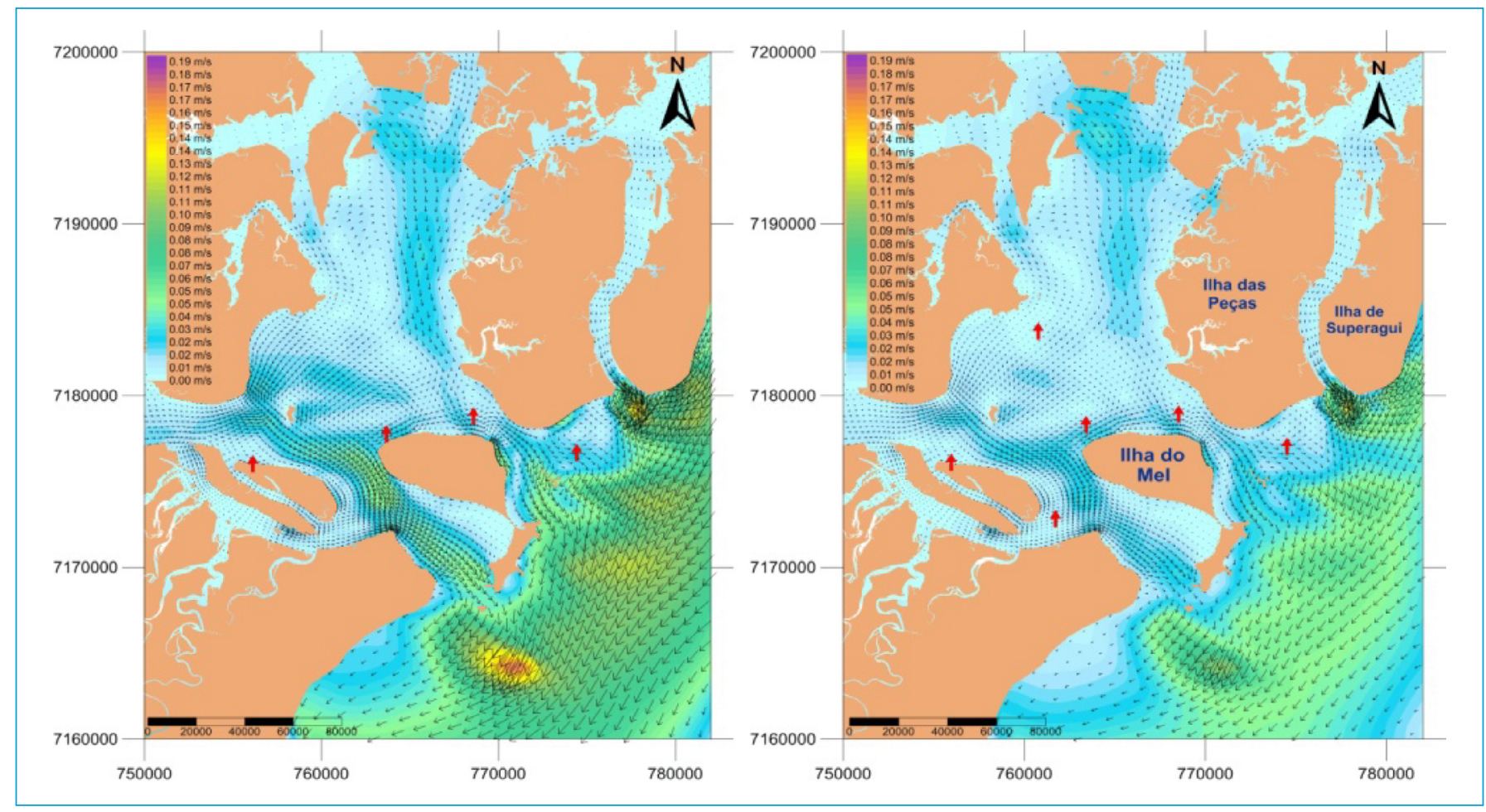

Figura 10 - Campo de correntes residuais (m/s) em sizígia ao longo de 25 horas para o cenário 3 (esquerda) e cenário 4 (direita), com a indicação dos vórtices no entorno da região da llha do Mel e da Ilha das Peças.

velocidades residuais reduzidas, quando comparadas com as demais áreas, o que corrobora a hipótese de que essas regiões podem indicar uma zona de mistura nesse estuário.

\section{CONCLUSÕES}

Neste trabalho foi apresentada uma aplicação dos modelos de circulação hidrodinâmica e de transporte do SisBaHiA ${ }^{\circledR}$, visando analisar o processo de renovação das águas do CEP. A aplicação da técnica de modelagem computacional mostrou-se eficaz ao representar a hidrodinâmica da região estudada; além disso, a criação e a simulação de cenários possibilitaram analisar a influência das forçantes hidrodinâmicas que governam o sistema estuarino.

Os cenários hidrodinâmicos criados se mostraram eficazes para apontar a maré e a vazão fluvial como forçantes de maior importância no processo de renovação das águas no CEP; a vazão fluvial tem papel importante como forçante, para garantir a renovação nas regiões próximas aos afluentes, e o vento mostrou ter pouca influência nos processos de renovação, sendo possível observar que em algumas regiões do CEP a inclusão do vento no modelo prejudica o processo de renovação, podendo indicar empilhamento da água na direção do interior da baía.

Em todos os cenários foi possível observar duas prováveis áreas de estagnação: a região da Baía dos Pinheiros e a região próxima à cidade de Paranaguá. Esses locais apresentaram menores TRs e maiores valores de IA do que o restante do CEP, tanto nos cenários representativos de verão como nos de inverno. Durante o verão e considerando-se todos os forçantes e após 3 meses de simulação, as TRs variaram entre 86 e 100\%, as TRs na região da Baía dos Pinheiros e na região próxima à cidade de Paranaguá são menores que $95 \%$ e as idades da água são maiores que 25 dias; nas demais regiões do CEP, os valores das TRs são superiores a $94 \%$ e as idades da água são menores que 10 dias. Essas regiões também apresentaram correntes residuais menores do que no restante do estuário, o que corroborou a hipótese de serem possíveis áreas de estagnação. Já a região da Baía de Antonina, por estar sob influência direta dos principais rios do CEP, pode ser demarcada como a Zona de Maré do Rio (ZR); a região entre a Baía de Antonina e a Baía de Paranaguá pode ser demarcada como a Zona de Mistura (ZM).

Por intermédio dos resultados obtidos neste trabalho foi possível analisar qualitativa e quantitativamente os processos de renovação das águas no CEP, permitindo inferir de forma mais precisa a dinâmica de constituintes presentes, bem como contribuir para a definição de zonas estuarinas. Além disso, por meio dos resultados foram identificadas possíveis áreas de estagnação, que podem ser consideradas como áreas de risco em casos de acidentes ambientais e de disposição inadequada de efluentes, de modo a subsidiar ações de gestão hídrica na região. 


\section{REFERÊNCIAS}

ADMINISTRAÇÃO DOS PORTOS DE PARANAGUÁ E ANTONINA (APPA); CENTRO DE ESTUDOS DO MAR (CEM). (2OO2) Relatório consolidado do convênio entre a Administração dos Portos de Paranaguá e Antonina e o Centro de Estudos do Mar/UFPR. Pontal do Paraná: FUNPAR. 2 v.

ADVANCED RESEARCH WRF (ARW). (2015) Version 3 Modeling System User's Guide. Mesoscale \& Microscale Meteorology Division, National Center for Atmospheric Research.

AGÊNCIA NACIONAL DE AGUAS (ANA). Hidroweb v.3.11. Brasil: ANA. Disponivel em: <http://www.snirh.gov.br/hidrowebs. Acesso em: jan. 2017.

BRASIL. (2001) Ministério da Pesca e Aquicultura. Grupo Integrado de Aquicultura e Estudos Ambientais. Planos Locais de Desenvolvimento da Maricultura. Paraná.

CARVALHO, G.C. (2015) Análise da sensibilidade do modelo WRF a diferentes configurações de regionalização dinâmica para modelagem da velocidade do vento. Dissertação (Mestrado em Engenharia Ambiental) - Universidade Federal do Paraná, Curitiba.

CUCCO, A.; UMGIESSER, G. (2006) Modeling the Venice Lagoon residence time. Ecological Modelling, v. 193, n. 1-2, p. 34-51. https:/l doi.org/10.1016/j.ecolmodel.2005.07.043

DALAZEN, J.P. (2017) Modelagem Numérica da renovação das águas no Complexo Estuarino de Paranaguá. Dissertação (Mestrado em Engenharia Ambiental) - Universidade Federal do Paraná, Curitiba.

DELHEZ, E.J.M. (2006) Transient residence and exposure times. Ocean Science, v. 2, p. 1-9. https://doi.org/10.5194/os-2-1-2006

DYER, K.R. (1973) Estuaries: A Physical Introduction. Nova York: John Wiley and Sons.

KENOV, I.A.; GARCIA, A.C; NEVES, R. (2012) Residence time of water in the Mondego estuary (Portugal). Estuarine, Coastal and Shelf Science, v. 106, p. 13-22. https://doi.org/10.1016/j.ecss.2012.04.008

LAMOUR,M.R.(2007)Morfodinâmicasedimentardadesembocadura do Complexo Estuarino de Paranaguá-PR. Tese (Doutorado em Geologia) - Universidade Federal do Paraná, Curitiba.

LANA, P.C.; MARONE, E.; LOPES, R.M.; MACHADO, E.C. (2O01) The subtropical estuarine complex of Paranaguá Bay, Brazil. In: SEELIGER, U.; KJERFVE, B. (org.). Coastal marine ecosystems of Latin America. Berlim: Springer, 2001. p. 131-145.

LOPES,J.F;:DIAS,J.M. (2007)Residualcirculationandsedimentdistribution in the Ria de Aveiro lagoon, Portugal. Journal of Marine Systems, v. 68, n. 3-4, p. 507-528. https://doi.org/10.1016/j.jmarsys.2007.02.005

MANTOVANELLI, A. (1999) Caracterização da dinâmica hídrica e do material particulado em suspensão na baía de Paranaguá e em sua bacia de drenagem. Dissertação (Mestrado em Geologia) Universidade Federal do Paraná, Curitiba.

MANTOVANELLI, A.; MARONE, E.; SILVA, E.T.; LAUTERT, L.F.; KLINGENFUSS, M.S.; PRATA JR., V.P.; NOERNBERG, M.A.; KNOPPERS, B.A.; ANGULO, R.J. (2004) Combined tidal velocity and duration asymmetries as a determinant of water transport and residual flow in Paranaguá Bay estuary. Estuarine, Coastal and Shelf Science, v. 59, n. 4, p. 523-537. https://doi.org/10.1016/j.ecss.2003.09.001

MARONE, E.; JAMIYANAA, D. (1997) Tidal characteristics and a numerical model for the M2 tide at the Estuarine Complex of Paranaguá Bay, Paraná, Brazil. Nerítica, v. 11, n. 1-2, p. 95-107.

MAYERLE, R.; NARAYANAN, R.; ETRI, T; WAHAB, A.K.A. (2015) A case study of sediment transport in the Paranagua Estuary Complex in Brazil. Ocean Engineering, v. 106, p. 161-174. https://doi.org/10.1016/j. oceaneng.2015.06.025

MONSEN, N.E.; CLOERN, J.E.; LUCAS, L.V.; MONISMITH, S.G. (2002) A comment on the use of flushing time, residence time, and age as transport time scales. Limnology and Oceanography, v. 47, n. 5, p. 1545-1553. https://doi.org/10.4319//o.2002.47.5.1545

NOERNBERG, M.A.; ANGELOTTI, R.; CALDEIRA, G.A.; SOUZA, A.F.R (2008) Determinação da sensibilidade do litoral paranaense à contaminação por óleo. Brazilian Journal of Aquatic Science and Technology, v. 12, n. 2, p. 49-59.

ROSMAN, P.C.C. (2017) Referência técnica do SisBaHiA. Rio de Janeiro: Escola Politécnica e da Área de Engenharia.

ROVERSI, F; ROSMAN, P.C.C.; HARARI, J. (2016) Análise da Renovação das Águas do Sistema Estuarino de Santos usando modelagem computacional. Ambiente \& Água, v. 11, n. 3, p. 566-585. https://doi.org/10.4136/ambi-agua.1770

SILVEIRA, L.U.; MIRANDA, T.L.G.; DIVIDINO, L.H.T.; FREGONESE, L.; VALENTE, A.M.; GIACOBO, F. (2012) Plano de desenvolvimento e zoneamento PDZPO do Porto de Antonina. Relatório técnico. Instituto de Tecnologia para o Desenvolvimento (LACTEC).

SKAMAROCK, W.C.; KLEMP, J.B.; DUDHIA, J.; GILL, D.O.; BARKER, D.M.; DUDA, M.G.; HUANG, X.; WANG, W.; POWERS, J.G.A. (2008) Description of the Advanced Research WRF Version 3. Boulder: National Center for Atmospheric Research.

XU, P.; MAO, X.; JIANG, W. (2016) Mapping tidal residual circulations in the outer Xiangshan Bay using a numerical model. Journal of Marine Systems, v. 154, parte B, p. 181-191. https://doi.org/10.1016/j. jmarsys.2015.10.002

ZIMMERMAN, J.T.F.; KJERFVE, B. (1988) Estuarine residence times. In: KJERFVE, B. (org.). Hydrodynamics of Estuaries. Boca Raton: Taylor \& Francis Group. v. 1. p. 75-84. 